Данилова Венедикта, доктор медицинских наук, невролог, Гилель Яффе медицинский центр, Хадера, Израиль; +(972)546567 027; vendidamilov@gmail.com

ORCID https://orcid.org /0000-0002-6029-1546

Козлов Михаил, доктор философии, директор Института интеграции и профессиональной адаптации, Нетания, Израиль; +(972)527 052 460; 19mike19k@gmail.com

ORCID https://orcid.org /0000-0003-4831-8571

\title{
О НЕКОТОРЫХ НЕГАТИВНЫХ ПОСЛЕДСТВИЯХ ДЕФОЛТНОГО СОСТОЯНИЯ МОЗГА
}

\begin{abstract}
Аннотация
Ключевые слова: тревожное состояние, субъектныемодели знаний, инфаркт, инсульт, вариабельность сердечного ритма.

Постановка проблемы. Рассмотрение механизма запуска нейрогуморальной регуляции в результате субъективной негативной оценки ситуации при дефолтном состоянии мозга (ДСМ), способного привести к катастрофическим последствиям для здоровья человека.

Анализ последних исследований. На основании проведенных исследований британскими и канадскими учеными были получены данные мета-анализабольных сострым инфарктом миокарда и с инсультом, указывающие на то, что люди, страдающие от сердечно-сосудистых заболеваний, чаще умирают ночью и по выходным дням.

Формулировка цели статьи. Цель - показать важность учета ДСМ и необходимость внедрения в повсеместную практику средств
\end{abstract}


систематического контроля тревожного состояния при профилактике сердечно-сосудистых заболеваний и заболеваний нервной системы.

Изложение основного материала. Рассмотрена корреляция увеличения смертности больных с инфарктами и инсультами в ночное время и выходные дни с особенностями работы дефолтной нервной сети мозга. Проведен анализ информации по ДСМ, работы памяти и принятия решений, влияния медитациинаДСМ, процедуры формирования состояния тревогииизмерения параметроввариабельности сердечного ритма. Даны рекомендации по организации контроля тревожного состояния.

Выводы и перспективы дальнейших исследований. Зависимость увеличения смертности больных с инфарктами и инсультами в ночное время и выходные дни следует рассматривать как многофакторную, и по каждому фактору возможности ее снижения необходимо рассматривать отдельно. Возможные субъектные негативные прогнозы ситуации во время ДСМ могут привести к запуску нейрогуморального регулирования с нежелательными последствиями. Этим можно объяснить связь увеличения количества инфарктов и инсультов со временем, в котором пациенты находятся в состоянии свободном от внешних раздражителей. Возникающие при ДСМ негативне эффекты необходимо учитывать в профилактике сердечнососудистых заболеваний, а также при целенаправленной разработке средств и методов предупреждения подобных ситуаций.

\section{Анотація}

Данилова Венедикта, доктор медичних наук, невролог; Гілель Яффе медичний центр, Хадера, Ізраїль. Козлов Михаїл, доктор філософії, директор Інституту інтеграції та професійної адаптації, Нетанія, Ізраїль. Про деякі негативні наслідки дефолтного стану мозку.

Ключові слова: тривожний стан, суб’єктні моделі знань, інфаркт, інсульт, варіабельність серцевого ритму. 
Постановка проблеми. Розгляд механізму запуску нейрогуморальної регуляції в результаті суб'єктивної негативної оцінки ситуації при дефолтному стані мозку (ДСМ), здатному привести до катастрофічних наслідків для здоров'я людини.

Аналіз останніх досліджень. На підставі проведених досліджень, британськими та канадськими вченими були отримані дані мета-аналізу хворих з гострим інфарктом міокарда та з інсультом, що вказують на те, що люди, які страждають від серцево-судинних захворювань, частіше вмирають вночі та у вихіднідні.

Формулювання мети статті. Мета -показати важливість урахування ДСМ i необхідність впровадження в повсюдну практику засобів систематичного контролю тривожного стану при профілактиці серцевосудинних захворювань і захворювань нервової системи.

Виклад основного матеріалу. Розглянуто кореляцію збільшення смертності хворих з інфарктами і інсультами в нічний час і вихіднідні 3 особливостями роботи дефолтної нервової мережі мозку. Проведено аналіз інформації по ДСМ, роботи пам'яті і прийняття рішень, впливу медитації на ДСМ, процедури формування стану тривоги і вимірювання параметрів варіабельності серцевого ритму.Надані рекомендаці щодо організації контролю тривожного стану.

Висновки i перспективи подальших досліджень. Залежність збільшення смертності хворих 3 інфарктами та інсультами в нічний час $\mathrm{i}$ вихідні дні слід розглядати як багатофакторну, і по кожному фактору можливості іiі зниження необхідно розглядати окремо. Можливісуб'єктні негативні прогнози ситуації під час ДСМ можуть привести до запуску нейрогуморального регулювання 3 небажаними наслідками. Цим можна пояснити зв'язок збільшення кількості інфарктів та інсультів з часом, в якому пацієнти знаходяться в стані, вільному від зовнішніх подразників. Виникаючі при ДСМ негативні ефекти необхідно враховувати в профілактиці серцево- 
судинних захворювань, а також при цілеспрямованій розробці засобів і методів попередження подібнихситуацій.

\section{Annotation}

Danilova Venedikta, MD, Neurologist; Gilel Jaffe Medical Center, Hadera, Israel. Kozlov Mikhail, Ph D, Director of the Institute for Integration and Professional Adaptation, Netanya, Israel. About some negative consequences of the brain condition.

Keywords: anxiety, subject know ledge models, heart attack, stroke, heart rate variability.

Formulation of the problem. Consideration of the mechanism for triggering Neurohumoral regulationas a resultof a subjective negative assessment of the situationin the default mode of brain function (DMBF), which can lead to disaster ous consequences for human health.

Analysis of recent research. Base don the research conducted by Britishand Canadian scientists, a meta-analysis of patients with acute myocardial infarction and stroke was obtained, indicating that people suffering from cardiovascular diseases of ten die at night and on weekends.

Formulating the purpose of the article. The purpose is to show the importance of accounting for DMBF and then eed to introduce in general practice the means of systematically controlling anxiety in the prevention of cardiovascular diseases and diseases of the nervous system.

Presenting main material. The correlation between the increase in mortality of patients with heart attacks and strokes at night and weekends withth epeculiarities of the work of the default mode network of the brain iscon sidered. The analysis of informationon DMBF, memory and decision making, the effects of meditationon DMBF, the procedure for generating anxiety and measuring heart rate variability parameters was carriedout. Recommendations on theorganization ofncontrol of anxiety are given. 
Conclusions and perspectives of further research. The dependence of the increase inmortality of patients with heart attack sand strokes at night and weekends should be considered as multifactorial, and for each factor the possibility of its reduction should be considered separately. Possible subjective enegative predictions of the situation during DMBF can lead to the launch of neurohumoral regulation with undesirable consequences. This may explain the connection between the increase in the number of heart attacks and strokes with time, in which patients are in a state free from external stimuli. Negative effects arising from DMBF must be considered in the prevention of cardiovascular diseases, as well as in the targeted development of means and methods to prevent such situations.

Ключевые слова: тревожное состояние, субъектныемодели знаний, инфаркт, инсульт, вариабельность сердечного ритма.

Постановка проблемы. Рассмотрение механизма запуска нейрогуморальной регуляции в результате субъективной негативной оценки ситуации при дефолтном состоянии мозга (ДСМ), способного привести к катастрофическим последствиям для здоровья человека.

Анализ последних исследований. Проанализировав результаты статистических данных мета-анализа 1,896,859 больных с острым инфарктом миокарда, авторы работы [1] пришли к результату, указывающему на то, что люди, страдающие от сердечно-сосудистых заболеваний, чаще умирают ночью и по выходным дням. Качество исследований оценивалось по шкале Newcastle-Ottawa, a неоднородность в мета-анализе была оценена с помощью Q статистики и $\mathrm{I}^{2}$ индекса. Полученные результаты авторы работы объясняют снижением в медицинских учреждениях в нерабочее время качества обслуживания и задержкой начала интенсивного лечения больных при ее необходимости.

К подобному заключению пришли канадские исследователи после анализа данных о 20,657 пациентах с первым острым инсультом [2] и 
британские ученые обследовавших 93621 пациента, поступивших с инсультом [3]. По их данным люди с инсультом, госпитализированные в выходные дни и ночью, имеют более высокий риск смерти по сравнению с пациентами, поступившими в больницу в рабочее время. Причину этого медики видят в ограниченном доступе к специалистам и процедурам вне рабочего времени. При этом по данным [3] «эффект выходного дня» был более выражен для пациентов в возрасте до 44 лет по сравнению с пациентами 85 лет и выше. В [4] отмечается, что около 60\% инсультов происходят ночью или в выходные дни, и в [5] говорится, что в выходные дни и ночью поступают более тяжелые больные. Все это усложняет процедуру лечения и в [4] рассматривается необходимость наличия многодисциплинарной команды в выходные дни и ночью, включая вспомогательных рабочих, рентгенологов, лаборантов и многих других специалистов для обеспечения оперативного и качественного лечения.

Признавая важность предложенных объяснений причин возникновения кризисных ситуаций при лечении больных с инфарктами и инсультами в ночное время и выходные дни, в [6] было предложено также учитывать, в качестве одного из важных причинных факторов, проявление нейрогуморального механизма регуляции в результате негативной оценки ситуации при ДСМ и приведено обоснование этому. Дополнительное разъяснение такого подхода далее будет рассмотрено.

Формулировка цели статьи. Цель - показать важность учета ДСМ и необходимость внедрения в повсеместную практику средств систематического контроля тревожного состояния при профилактике сердечно-сосудистых заболеваний и заболеваний нервной системы.

Изложение основного материала. Постараемся объяснить некоторые аспекты временной статистики инфарктов и инсультов. Во время сна или в период длительного полного отдыха при отсутствии непрерывно поступающих раздражителей, на которые требуется обращать внимание, мозг в дефолтном состоянии продолжает интенсивно обрабатывать ранее 
поступившую информацию [7]. Наиболее продуктивно такая обработка происходит во время сна. Когда в течение дня в память человека поступает разрозненная внешняя информация, содержащая негативные стрессовые факторы, или информация о внутренних болезненных нарушениях и формируется тревожное состояние, то в первую стадию сна в течение нескольких сот низкочастотных циклов в дефолтной нервной сети (ДНС) происходит упорядочение поступившей информации и выработка негативных прогнозов, что усиливает тревожное состояние. В процессе достаточно длительного и безуспешного поиска решений для выхода из такой ситуации, тревожное состояние закрепляется в течение последующихсвободных от внешних раздражителей часов за сет обратных связей ДНС. При этом невозможность выработки решения и субъектноориентированная эмоциональная оценка безысходности ситуации приводит к паническому состоянию. Такая реакція мозга, за сет нейрогуморального механизма регуляции, изменяет функциональное состояние организма, что, в свою очередь, как правило, в середине ночи, может вызвать катастрофические последствия, и в первую очередь, для людей с сердечнососудистыми заболеваниями. Это может стать причиной внезапной смерти во время сна или полного отдыха больных людей. Известны также свидетельства того, что во время сна умирают достаточноз доровые люди в день, совпадающий календарно с днем, в котором несколько лет назад у них произошел трагический случай. С большой долей вероятности, можно допустить, что такие смерти являються следствиями циклических процесов в ДНС и формировании при этом крайне тривожного состояния.

В [8] представлены исследования стрессового состояния двух наблюдавшихся групп - здоровых людей и больных, для которых измерения были проведены через несколько дней после инфаркта миокарда. Оценки стрессового состояния в обеих группах испытуемых были получены во время бодрствования, на стадии парадоксального (быстрого) сна (REM), который отражает процессы, проходящие в ДНС, и на 
стадии медленного сна (NREM). В качестве оценки стрессового состояния использовалось отношение LF/HF (индекс вагосимпатического взаимодействия), где LF - мощность низкочастотной составляющей спектра вариабельности сердечного ритма (BCP), aНF - мощности высокочастотной составляющей спектра ВСР.

Приведенные в [8] статистические данные оценок отношений LF/HFво время бодрствования и разных стадий сна для здоровых и больных людей для удобства анализа отобразим в следующей таблице 1.

Таблица 1.

\section{Оценки стрессового состояния LF/HF}

\begin{tabular}{|l|l|l|l|}
\hline $\begin{array}{l}\text { Группы } \\
\text { наблюдения }\end{array}$ & $\begin{array}{l}\text { Состояние } \\
\text { бодрствования }\end{array}$ & $\begin{array}{l}\text { Стадия пара- } \\
\text { доксального } \\
\text { (REM) сна }\end{array}$ & $\begin{array}{l}\text { Стадия } \\
\text { медленного } \\
\text { (NREM) cна }\end{array}$ \\
\hline Здоровые люди & $4.0 \pm 1.4$ & $3.1 \pm 0.7$ & $1.2 \pm 0.4$ \\
\hline $\begin{array}{l}\text { Больные после } \\
\text { инфаркта миокарда }\end{array}$ & $2.4 \pm 0.7$ & $8.9 \pm 1.6$ & $5.1 \pm 1.4$ \\
\hline
\end{tabular}

Как видно из этих данных, у здоровых людей во время REM сна стрессовое состояние меньше, чем во время бодрствования, а также значительно меньшево время NREM сна, что свидетельствует о значительном расслаблении организма здоровых людей на этих стадиях сна. Для больных людей перенесших инфаркт миокарда оценки стрессового состояния имеют противоположную тенденцию. Для этой группы больных людей в состоянии бодрствования индекс вагосимпатического взаимодействия был меньше, чем у группы здоровых людей. Однако по сравнению со здоровыми людьми на стадии REM сна оценка стрессового состояние оказалась в несколько раз больше и значительно меньше снизилась во время NREM сна. Учитывая корреляцию ДСМ и стадию REM сна можно сделать вывод, что у группы больных людей во время ДСМ состояние тревожности значительно возрастает и продолжает некоторое время сохраняться на стадии NREM сна. С другой стороны, у этой группы больных во время бодрствования наступает релаксация, что может отражать их 
эмоциональное состояние в период восстановления и неравноценность состояния бодрствования у здоровых и больных людей.

Далее рассмотрим процедуру формирования субъективной оценки. Нарастающее тревожное и даже паническое состояние может происходить в ДСМ не обязательно во время сна. Оно может появиться у человека в свободное время, когда его ничто не отвлекает и он предоставлен своїм мыслям. У некоторых, часто нездоровых людей, такое состояние может появиться вечером, перед сном.

В рассматриваемых случаях, негативне раздражители не являються напрямую основанием для выхода параметров нейрогуморального механизма регуляции на критические уровни для поддержания гомеостаза, а лишь начальным толчком для запуска итерационной процедуры выработки сугубо субъектного решения при ДСМ.

Выработку решений в активном и дефолтном состояниях мозга можно рассматривать на основе компьютерно-мозговой модели памяти и принятия решений [9], приведенной на рисунке 1. По этой модели, в результате развернутой во времени адаптивной итерационной процедуры, в аттракторах памяти происходит формирование субъектных моделей знаний (CM3).

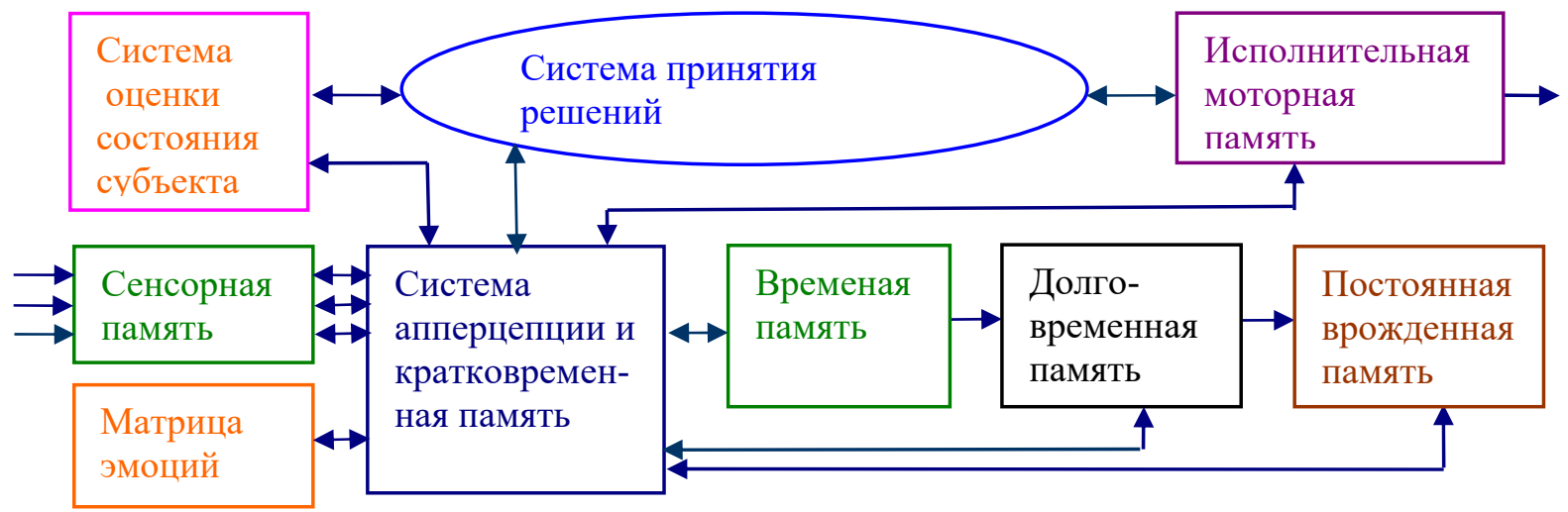

Рис. 1. Субъектно-ориентированная модель памятии принятия решений

Поступающая к человеку внешняя информация и информация о его состоянии с учетом эмоционального вектора проходит процедуру апперцепции и заносится в кратковременную (рабочую) память (КП). КП участвует не только в обработке входной информации, но и в дальнейшем 
упорядочении сформировавшихся знаний и в выработке решений. Такая процедура затруднена при активном реагировании человека на внешние сигналы в состоянии бодрствования из-за ограниченной пропускной способности КП, которая, по данным [10], в среднем находится около четырех чанков (chunk), неких смысловых образов.

Таким образом, в состоянии бодрствования формирование сложных СМЗ затруднено. Однако природа нашла превосходное решение по повышению эффективности интеллектуального аппарата. Во время сна или в период отдыха мозг переходит в дефолтное состояние. При этом автогенерация сложных СМЗ будет происходить по внутреннему контуру в мозге через цепи обратных связей, идущих от разных участков памяти на КП, а не на основе поступающей внешней информации. Каждый раз при поступлении СМЗ в КП производитсяихноваяэмоциональнаяоценка, осуществляя как бы новое их осознание. В процессе генерации все более сложных СМЗ происходит увеличение веса более достоверных для субъекта моделей знаний и подавление других СМЗ [9].

Для консолидации СМЗ необходимо наличие эмоциональной оценки события, дефолтного состояния мозга и времени на формирование СМ3 в этом состоянии. Этим можно объяснить результаты исследований эмоционально шокирующего воздействия на человека [11], показавшие селективное и ретроактивное усиление воспоминания, после 6 часов и более, о произошедшем в паре с шоком событии.

Субъектно-ориентированная система выработки и принятия решений в результате последовательных действий обратных связей ДНС резонансно настраивается по отношению к раздражителю, исходная информация о раздражителе будет составлять лиш малую долю всей обрабатываемой информации для формирования сложной СМЗ .

Необходимо учитывать, что тревожное состояние формируется в основном при многократном поступлении раздражителей, оцениваемых как негативные. При этом, за счет механизма апперцепционной фильтрации, в 
активном состоянии мозга во временной памяти будет накапливаться преимущественно негативная информация. В тревожном состоянии будет происходить ограничение набора возможных вариантов ассоциативных связей до определенного минимума, необходимого для ускоренного реагирования на текущую ситуацию, и в результате снижается урівень достоверности вырабатываемых решений [9].

При ДСМ возможно, по результатам анализа получаемой мозгом информации от внутренних органов, по цепи обратной связи мозг-тело, целенаправленное регулирование происходящих в отдельных органах процессов, как в положительную сторону, что отмечается человеком по улучшению его состояния, после пробуждения, так и возможное разрегулирование при субъективно-неблагоприятных прогнозах. Так в [12] приводится информация о негативном влиянии процессов, протекающих при ДСМ, на развитие болезни Альцгеймера в случаях возникновения повышенной возбудимости больных. Можно предположить, что подобное влияние происходит в ДСМ и при других неврологических расстройствах.

Рассмотрим возможности профілактики негативних эффектов ДСМ. Говоря о предупреждении формирования негативних прогнозов в ДСМ, отметим, что они являються следствием субъектного восприятия поступающих раздражителей, и при тревожности в КП будет поступать информация с адекватними состоянию эмоциональными оценками. Поэтому, в качестве профилактических мер, целесообразно в активном состоянии мезга снабжать его положительно окрашенной информацией, в том числе, и с помощью психотерапевтических воздействий. Влияние на процессы, происходящие во время сна, можно производить с применением медикаментозних средств. Для снижения негативного влияния ДСМ в состоянии отдыха, в [12], в качестве профилактической меры, предлагается использование медитации и показывается, по результатам исследования с помощью фМРТ, подавление активности ДНС при медитации. 
Рассмотрим возможные средства контроля тревожного состояния. Для проведения инструментального контроля тревожного состояния в период бодрствования и во время ДСМ, возможно использование оценок, получаемых на основе применения весьма эффективных методов анализа состояния вегетативной нервной системы человека, основанных на измерении параметров вариабельности сердечного ритма (ВСР) [13].

Оценка уровня тревожного состояния на основе анализа параметров ВСР, количественно хорошо отражает степень напряжения регуляторных систем в цепи «мозг-тело» в ответ на стрессовое воздействие. Такая оценка не трудоемка. Исходными данными для анализа ВСР является числовая выборка из измеренных длительностей последовательного ряда кардиоинтервалов. Измерение длительностей кардиоинтервалов возможно на основе различных физиологических процессов происходящих в течение сердечных циклов. Измерения могут производиться на основеданных электрокардиографии (ЭКГ), регистрации частоты пульсации крови в артериях с помощью различного вида датчиков и акустических измеренийтонов сердца.

При использовании данных ЭКГ, за длительность кардиоинтервала принимается интервал RR между вершинами соседних R-зубцов [13]. Метод измерения ВСР на основе данных ЭКГ рассматривается как золотой стандарт по отношению к другим методам, так как позволяет более точно идентифицировать кардиоинтервалы. Однако этот метод не удобен при повседневном использовании и получили распространение методы измерения параметров пульсовой волны на основе плетизмографии. Плетизмография позволяет оценивать гемодинамические показатели организма в виде объёмной скорости кровотока и ударного выброса. Широко используемой разновидностью плетизмографии является фотоплетизмография (ФПГ), основанная на измерении оптической плотности исследуемой ткани тела путем ее освещения инфракрасным лучом и приемом пройденного через ткань сигнала оптоэлектронным датчиком. 
В ряде случаев, появляется необходимость в периодическом или постоянном бесконтактном контроле параметров ВСР у людей по их медицинским показателям, например, у младенцев с чувствительной к инфекции коже, ожоговых больных, или по их профессиональной деятельности, таких как пилотов самолетов, диспетчеров, водителей общественного транспорта, космонавтов [14]. Такой совершаемый на определенном расстоянии от испытуемого бесконтактный контроль ВСР, происходящий без участия и ведома контролируемого лица, является наиболее приемлемым и комфортным средством контроля состояния здоровья. Бесконтактные методы измерения таких жизненно важных параметров как частота пульса и частота дыхания могут оказаться удобными как в условиях стационара, так и, особенно, вне его.

Надежная дистанционная система ФПГ для измерения частоты пульса, вариабельности частоты пульса и частоты дыхания рассмотрена в [15]. Такая система по видеозаписи лица с помощью веб-камеры позволяет получать достаточную для клинических целей точность измерений для всех тонов кожи человека. Для этого в разных областях видимой кожи измеряются мельчайшие изменения цвета кожи, происходящие в результате изменения подкожного объема крови. К положительным особенностям видеозаписи с помощью веб-камеры при ФПГ можно отнести мобильность устройства, а также возможность контроля многих лиц одновременно.

Для повышения достоверности получаемых результатов, необходимо использовать аппаратно-программные комплексы (АПК), которые позволят накапливать данные, анализировать в автоматическом режиме, производить статистическую обработку данных для выявления индивидуальных связей у пациентов между тревожностью и параметрами ВСР, прогнозировать ситуацию и выдавать рекомендации. И все это делать оперативно.

В [16] рассматривается необходимость с помощью выполняющих анализ ВСР автоматизированных систем донозологической диагностики проводить регулярный индивидуальный контроль функционального 
состояния практически здоровых людей с донозологическими и преморбидными состояниями. Для снижения влияния человеческого фактора на безопасность полетов в [17] предлагается использовать АПК для контроля ВСР у пилотов.

Для массового применения АПК потребуется разработка адаптируемого под каждого индивидуума программного обеспечения, которое позволит проводить субъектно-ориентированную обработку входящих данных на основе индивидуальных особенностей пациентов и соответствующую выработку индивидуальных рекомендаций по реагированию на изменяющуюся ситуацию. Современные технологии обработки большого потока данных (BigData), с концентрацией информации колоссальных объемов, позволят составлять индивидуальный профиль каждого пациента на основе анализа его текущих данных, поступающих в АПК. Использование автоматизированного АПК для оценки уровня тревожного состояния с применением методов интеллектуального анализа данных позволит упростить и ускорить процедуру массового контроля пациентов и повысить его качество. В условиях больницы, АПК позволит повысить оперативность реагирования на чрезвычайные ситуации и концентрировать в первую очередь на них внимание медицинского персонала, что повысит как качество обслуживания, снижения количества негативных исходов так и уменьшит нагрузку на персонал и даст возможность снижения необходимого его количества. В дальнейшем на основе таких АПК можно создавать систему массового охвата всего населения по контролю за состоянием людей, с выводом этой информации лечащим врачам, позволяющую проводить им соответствующие профилактические мероприятия.

В качестве дополнительного обсуждения рассматриваемой темы, можно говорить о том, что организм человека является сложной адаптивной саморегулирующей системой, учитывающей в своей работе множество факторов состояния внешней среды и состояния его внутренних органов. 
Поэтому рационально рассматривать его функционирование, как процедуру сложного взаимодействия «мозг-тело». У больных людей повышается вероятность наступления тревожного состояния при субъективно оцениваемых факторах окружающей среды, как негативных. В связи с этим информация, поступающая пациентам о надежности их обслуживания в нерабочее время, в соответствии с мерами, предлагаемыми в $[1,4]$ по повышению качества такого обслуживания, может снизить вероятность возникновения тревожности у больных (эффект плацебо). Дополнительно к эффекту от фактического повышению качества обслуживания пациентов в нерабочее время, это позволяет изменить статистику зависимости от времени количества инфарктов и инсультов. В то же время, в качестве значительного влияющего фактора, предлагается считать нейрогуморальный механизм регуляции, возникающий в результате субъективной негативной оценки ситуации при ДСМ. Такой взгляд может повлиять на разработку методов предупреждению кризисных состояний у пациентов.

В качестве яркого примера влияния психологического фактора на статистику смертности при сердечных заболеваниях можно привести случаи 209,908 смертей американцев японского и китайского происхождения [18]. Исследования показали, что среди этой категории американцев число смертей от сердечных приступов по 4-м числам каждого месяца на 7\% выше, чем в другие дни, причем для хронических больных эта цифра достигает $13 \%$. Это связано с тем, что этот день считается у японцев и китайцев самым плохим, и ими испытывается дополнительный психологический стресс. Такой подъем смертности был назван «эффектом Баскервиля», по названию рассказа Конан Дойля, описавшего смерть страдавшего хронической болезнью сердца человека из-за сильного психологического стресса.

В свете рассмотренного, интересна статистика ночных инфарктов у людей, читающих на ночь молитвы и таким образом через КП заносящих во временную память дополнительную информацию, отвлекающую от повседневной деятельности, и у людей, не делающих этого. Априори можно 
предположить положительную статистику у молящихся на ночь людей. Во всяком случае, по данным исследований более 5000 человек Институтом изучения религии университета Бейлор среди четырех крупных еврейских общин США, те люди, которые регулярно посещают синагогу, значительно лучше себя чувствуют, чем светские или нерелигиозные евреи. Подобное просматривается среди христиан с сильным религиозным чувством [19].

Из приведенных в [20] данных о распределении по времени суток частоты родов следует, что явно выраженный пик с размахом до 40\% по количеству начальных схваток и самих родов приходится на время между 2 и 5 часами ночи. В [21], на основе взятой в Японии за трехлетний период достаточно представительной выборки данных о 4,411 родах, приведены статистические данные недельного распределения рождений детей, из которых видно, что в выходные дни рождаемость значительно ниже. Если суточное распределение количества родов можно связывать с циркадными биоритмами, то с недельной адаптацией вопрос сложнее. Можно предположить, что здесь во время ДСМ происходят процессы, приводящие не к ускорению, а к торможению исхода, в данном случае, начала родовых схваток. В связи с этим, представляет интерес статистика количества родов в праздничные и рабочие дни. Естественно для этого придется брать выборку по значительно большему их количеству и за большой промежуток времени.

Была бы интересна подобная статистика распределения по времени осложнений хронических заболеваний.

Использование методов контроля состояния людей на основе анализа параметров ВСР весьма перспективно для широкого применения. Так в [22] используя данные о снижении ВСР у пациентов с психическими расстройствами при применении психотропных препаратов подчеркивается необходимость для снижения риска сердечно-сосудистых заболеваний модификации лечебных процедур. По мнению [23] данные анализа ВСР обладают предикторной ценностью и могут эффективно применяться в различных областях медицины с целью стратификации риска и диагностики, 
особенно у пациентов с сердечно-сосудистыми заболеваниями, включая внезапную сердечную смерть. В [24] рассматривается возможность использования оценок ВСР как потенциальный предиктор хода развития ишемического инсульта у пациентов с момента поступления их в клинику. И, по-видимому, анализ ВСР станет достаточно эффективным независимым инструментом в процессе лечения таких больных.Контроль состояния здоровья в амбулаторных условиях с помощью анализа ВСР может повысить профилактический уровень по ряду заболеваний и можно предположить, что использование индивидуальных средств измерения параметров ВСР станет нормой цивилизованного поведения.

Учитывая повышенную реактивность человека, находящегося в тревожном состоянии, для исключения негативного воздействия наблюдателя на результат наблюдения следует рассматривать, в некоторых случаях, например, при возможности оперативного реагирования медицинского персонала, необходимость проведения измерений в автоматическом режиме без предоставления пациенту результатов текущего анализа ВСР. Иначе это может в замкнутой системе тело-мозг привести к дополнительной и иногда существенной разбалансировке его нервногуморального механизма регуляции (эффект ноцебо).

Используя результаты исследований нейронауки, на основе методов анализа ВСР можно рассматривать целесообразность проведения разработки аппаратных средств оперативного контроля процессов, проходящих во время ДСМ и, при неблагоприятной ситуации, приманять возможные способы разрыва в ДНС цепочки формирования оценок, усиливающих тревожное состояние, или ослаблять некоторые нервные связи в системе «мозг-тело».

Выводы и перспективы дальнейших исследований. Зависимость увеличения смертности больных с инфарктами и инсультами в ночное время и выходные дни следует рассматривать как многофакторную, и по каждому фактору возможности ее снижения необходимо рассматривать отдельно. 
Возможные субъектные негативные прогнозы ситуации во время ДСМ могут привести к запуску нейрогуморального регулирования с нежелательными последствиями. Этим можно объяснить связь увеличения количества инфарктов и инсультов со временем, в котором пациенты находятся в состоянии свободном от внешних раздражителей. Таким образом, возникающие негативныеэффекты при ДСМ необходимо учитывать в профилактике сердечно-сосудистых заболеваний и заболеваний нервной системы, а также при целенаправленной разработке средств и методов предупреждения подобных ситуаций.

Проведенный анализ и сделанные выводы дают возможность целенаправленно разрабатывать мероприятия по профилактике таких заболеваний. Внедрение в повсеместную практику средств систематического контроля тревожного состояния может помочь в сохранении здоровья.

\section{Список использованных источников}

1. Sorita, A. et al. Off-hour presentation and outcomes in patients with acute myocardial infarction: systematic review and meta-analysis.- BMJ, 2014;

2. Saposnik G. et al. A Dangerous Time for Having a Stroke? Stroke 05/2007; 38(4): P. 1211-15.

3. Palmer W. L. et al. Dying for the Weekend: A Retro spective Cohort Study on the AssociationBetween Day of Hospital Presentation and the Quality and Safety of Stroke Care. Arch. Neurol.,2012; 69(10): P. 1296-1302.

4. Rudd A. G., Bray B. Strokes happen round the clock, but why is stroke care worse on weekends and overnight? J NeurolNeurosurg Psychiatry.2015.

5. Campbell J. T. et al. The effect of out of hours presentation with acute stroke on processes of care and outcomes: analysis of data from the Stroke Improvement National Audit Programme. Intercollegiate Stroke Working Party. Feb. 2014.

6. V. Danylov, S. Kletskin, M. Kozlov. Negative manifestation the defolt mode of brain function.The Bulleten of Academy. Israeli Independent Academy of Development of Science. Haifa, Iarael, 2016. Vol.8, №1- P.3-12. 
7. Marcus E. Raichle, Abraham Z. Snyder. A defaultmodeofbrainfunction: A briefhistoryofanevolvingidea/ NeuroImage 37 (2007). —P. 1083 - 1090.

8. Vanoli E. et al. Heart rate variability during specific sleep stages.A comparison of healthy subjectswith patients after myocardial infarction.Circulation, 1995, 91. P. 1918-1922.

9. Kozlov M. Computer-brain model memory and decision-making.The Bulleten of Academy. Israeli Independent Academy of Development of Science. Haifa, Israel, 2017. Vol.9, №1 - P. 27-45.

10. Nelson Cowan. The magical number 4 in short-term memory: A reconsideration of mental storagecapacity. Behavioral and Brain Sciences (2000) 24, P. 87-185.

11. Dunsmoor J. E., Murty V. P., Davachi L., Phelps E. A. Emotional learning selectively and retroactively strengthens memories for related events // Nature. January, 2015.

12. Brewer J. A. et al. "Meditation training is associated with differences in default mode networkactivity and connectivety." PNAS 108(50),2011.- P.20254-9.

13. Клецкин С. Ритм сердца как индикатор состояния организма. Изд-во «Достояние». Иерусалим, 2017.

14. Perry, C.M. Watkins, S. Non-Contact Vital Sign Monitoring via UltraWideband Radar, Infrared Video, and RemotePhotoplethysmography: Viable Options for Space ExplorationMissions. NASA / TM-2011-216145.

15. Kumar, M. Veeraraghavan, A. Sabharwal, A. "DistancePPG: Robust noncontact vital signsmonitoring using a camera," Biomed. Opt. Express 6, 2015. - P. 1565-1588.

16.Баевский Р. М., Берсенева А.П. Введение в донозологическую диагностику. - М.: Слово, 2011.

17. Kozlov M.Ways reduce the impact of human factors on safety the flights. NIZI.co.il / Science andlife Israel.14.04.2015. 
18. Phillips D. P., Liu G. C., Kwok K. et al. The Hound of the Baskervilles effect: natural experimenton the influence of psychological stress on timing of death. BMJ, 2001; 323: P. 1443-1446.

19. Levin J. Religious Differences in Self-Rated Health Among USJews: Findings from Five Urban Population Surveys. J Relig Health. January 2015.

20. Kaiser I. H, Halberg F. Circadian periodic aspects of birth. Ann NY Acad Sci. 1962; v. 98 - P. 1056-1068.

21. Yamanaka T. et al. Further Mapping of the Natality Chronome in Toda City (Japan) Maternity Hospital.Scr Med (Brno) 78(2), 2005 - P. 99-106.

22. Alvares G. A. et al. Autonomic nervous system dysfunction in psychiatric disorders and the impactof psychotropic medications: a systematic review and metaanalysis. JPsychiatryNeurosci. 2016 Mar; 41(2): P. 89-104.

23. Бокерия Л. А., Бокерия О. Л., Волковская И. В. Вариабельность сердечного ритма: методы измерения, интерпретация, клиническое использование. Анналыаритмологии. № 4.т.6, 2009 - с. 21-32.

24. Chen, C.-H. et al. Complexity of Heart Rate Variability Can Predict StrokeIn-Evolution in AcuteIschemic Stroke Patients. Sci. Rep. 5, 17552; 2015.

\section{References}

1. Sorita, A. et al. (2014), Off-hour presentation and outcomes in patients with myocardial infarction: systematic review and meta-analysis, BMJ.

2. Saposnik, G. et al. (2007), “A Dangerous Time for Having a Stroke?", Stroke, vol. 38 (4), pp. 1211-15.

3. Palmer, W. L. et al. (2012), "Dying for the Weekend: A Retro spective Cohort Study Stroke Care”, Arch. Neurol., vol. 69 (10), pp. 1296-1302.

4. Rudd, A. G. (2015), "Strokes”, J Neurol Neurosurg Psychiatry.

5. Campbell. J. T. et al. (2014), "Stroke Improvement National Audit Program", Intercollegiate Stroke Working Party. 
6. Danylov, V. Kletskin, S. Kozlov, M., (2016), "Negative manifestation of the defolt mode of brain function", The Bulleten of Academy. Israeli Independent Academy of Development of Science, vol.8 (1), P. 3-12.

7. Marcus E. Raichle, Abraham Z. Snyder (2007), A default mode of brain function: A brief history of anevolving idea, NeuroImage.

8. Vanoli, E. et al. (1995), "Heart rate variability during specific sleep stages. A comparison of healthy subjects with patients after myocardial infarction", Circulation, vol. 91., pp. 1918-1922.

9. Kozlov, M. (2017), “Computer-brain model memory and decision-making”, The Bulleten of Academy. Israeli Independent Academy of Development of Science, vol. 9 (1), pp. 27-45.

10. Nelson Cowan (2000), "The reconsideration of mental storage storage capacity", Behavioral and Brain Sciences, vol. 24, pp. 87-185.

11. Dunsmoor, J. E. Murty, V. P., Davachi, L., Phelps, E. A. (2015), "Emotional learning selectively and retroactively strengthens memories for related events", Nature.

12. Brewer, J. A. et al. (2011), "Meditation training is associated with differences in default mode network activity and connectivety", PNAS, vol. 108 (50), pp.20254-9.

13. Kletskin, S. (2017), Heart rhythm as an indicator of the state of the body. Publishing house, "Property". Jerusalem,Israel.

14. Perry, C. M. (2011), Watches, $S \&$ V Infrared, Radar, Infrared Video, and InfraPhotoplethysmography: NASA,TM-2011-216145.

15. Kumar, M. Veeraraghavan, A. Sabharwal, A. (2015), "DistancePPG: Robust non-contact signs signs monitoring using a camera", Biomed. Opt. Express, vol. 6, pp. 1565-1588.

16. Baevsky, R. M. Berseneva, A. P. (2011), Introduction to prenosological diagnostics, Slovo, Moscow, $\mathrm{Ru}$.

17. Kozlov, M. (2015), "Ways reduce the impact of human factors on safety of flights. NIZI.co.il", Science and life Israel, Israel. 
18. Phillips, D.P. Liu, G.C., Kwok, K. et al. (2011), "The effect of natural stress on timing of timing”, BMJ, vol. 323, pp. 1443-1446.

19. Levin, J. (2015), "Religious Self-Rated Health Among the Five Urban Population Surveys", J Relig Health.

20. Kaiser, I. H Halberg, F. (1962), "Circadian periodic aspects of birth", Ann NY Acad Sci, vol. 98, pp. 1056-1068.

21. Yamanaka, T. et al. (2005), "Chronome in Scala", Med (Brno), vol. 78 (2), pp. 99-106.

22. Alvares, G. A. et al. (2016), “Autonomic nervous system dysfunction in psychiatric disorders and the psychotropic medications: a systematic review and metaanalysis", JPsychiatryNeurosci, vol. 41 (2), pp. 89-104.

23. Bockeria, L. A. Bockeria, O. L. Volkovskaya, I. V. "Heart rate variability: measurement methods, interpretation, clinical use", Annaly arhythmology, vol. 4 (6), pp. 21-32.

24. Chen, C.-H. et al. (2015), "Complexity of Heart Rate Variability in Acute Ischemic Stroke Patients", Sci. Rep., vol. 5, 17552. 